\title{
DYNAMICS OF ENERGY SUBSTRATES IN THE HAEMOLYMPH OF LOCUSTA MIGRATORIA DURING FLIGHT
}

\author{
D. J. VAN Der Horst, N. M. D. Houben and A. M. Th. Beenakkers \\ Laboratory of Chemical Animal Physiology. State University of Utrecht. 8 Padualaan. Litrecht. \\ The Netherlands
}

(Received 20 November 1979)

\begin{abstract}
In the two-fuel system for flight of the migratory locust, the haemolymph carbohydrate concentration falls during flight periods of up to $1 \mathrm{hr}$, the decrease being greater in case the pre-flight carbohydrate level is higher. The increase in the lipid concentration from the onset of thight is virtually independent of the initial lipid concentration. Flight intensity affects these changes in substrate concentrations: the carbohydrate level decreases more rapidly if flight speed is higher, whereas the increase in lipid concentration is delayed at higher flight speeds. Respiratory carbon dioxide production is elevated rapidly during flight and reaches over eight times the resting level. From the rate of ${ }^{1+} \mathrm{CO}_{2}$ production after labelling of the haemolymph diglyceride pool it is concluded that diglycerides contribute to providing the energy for flight from the earliest stage of flying activity: diglyceride oxidation increases until maximum utilization is attained after some $45 \mathrm{~min}$ of flight. The decline in haemolymph carbohydrate concentration due to flying activity results in a decrease of haemolymph osmolarity. Free amino acids, particularly taurine. increase markedly in the haemolymph during flight: yet their concentration only partially counterbalances the fall in haemolymph osmolatity.

Key Word Index: Locust, flight. transport. carbohydrate, diglyceride. energy supply. oxidation
\end{abstract}

\section{INTRODUCTION}

THE FLIGHT muscles of Locusta migratoria are capable of oxidizing both carbohydrate and lipid for energy production (BEENAKKERS, 1969a; CANDY, 1970). During muscular exercise, however. utilization of these substrates is non-random, since initially carbohydrate is the predominant energy source whereas during prolonged flight lipids constitute the main fuel (WEIS-FOGH, 1952; MAYER and CANDY, 1969a: JUTSUM and Goldsworthy. 1976; VAN DER HORst et al., 1978a, b).

As metabolic substrates for flight are conveyed through the haemolymph, the control of haemolymph substrate levels would appear to be of major importance to flight performance. The high concentration of haemolymph trehalose in the resting locust declines rapidly in the initial period of flight, whereas conversely already in an early stage of flying activity lipid oxidation in the flight muscles is anticipated by an increase in the concentration of haemolymph diglycerides mobilized from fat body lipid stores (TIETZ, 1967) by the action of the adipokinetic hormone released from the corpora cardiaca (BEENAKKERS, 1969b; MAYER and CANDY, 1969b: Goldsworthy et al., 1972). Despite the involvement of lipoproteins in the transport of these diglycerides (Mayer and Candy, 1967; Peled and TIETZ. 1975; MWANGI and GOLDSWORTHY, 1977; VAN DER HORST et al.. 1979) haemolymph total protein concentration remains unaffected during flight (MWANGI and GOLOSWORTHY, 1977: VAN DER HORST et al. 1979).
During extended flight, the reciprocal changes in the concentrations of haemolymph trehalose and diglycerides eventually result in the stabilization of steady state levels of both substrates exhibiting different turnover rates (VA.: DER HORST et al., $1978 \mathrm{a}, \mathrm{b})$.

The present study is concerned with the first period $(60 \mathrm{~min})$ of flight, in which the energy substrate concentrations in the haemolymph are balanced. and deals particularly with the effects of the pre-flight levels of haemolymph carbohydrate and lipid and of flight intensity on the dynamics in the concentrations of these substrates. Besides. respiration experiments were carried out to correlate the changes in haemolymph substrate concentration with the actual substrate utilization in the flight muscles. As the changes in haemolymph carbohydrate concentration perturb blood osmotic pressure, a possible regulatory function of free amino acids was also investigated.

\section{MATERIALS AND METHODS}

Adult males of Locusta migratoria (12-1+ days after the imaginal ecdysis) were used in all experiments. The locusts were reared in the laboratory under crowded conditions at $30^{\circ} \mathrm{C} .40^{\circ}, \mathrm{r}$ r.h. and a photoperiod of $12 \mathrm{hr}$. The insects were fed with reed supplemented with rolled oats.

\section{Flight experiments}

Flight experiments were carried out at an ambient temperature of $25 \pm 1^{\circ} \mathrm{C}$ in three different ways: 
(a) In a series of experiments. locusts were flown in groups of 5-15 suspended on a motor-driven roundabout (100 cm radius) rotating at a constant speed ( $3 \mathrm{~m}$, sec). From each locust, haemolymph lipid and carbohydrate concentrations were measured before and after flight. Free amino acid concentrations were determined in pooled haemolymph samples of ten locusts.

(b) In another series, the effect of flight intensity on changes in haemolymph substrate concentrations was studied by flying locusts individually on a roundabout (25 cm radius) without mechanical propulsion. The number of revolutions flown in a certain period as registered by a light-sensitive switch connected to an electronic counter was used as a measure for flight intensity.

(c) In a third series of experiments, respired carbon dioxide during flight was measured. Groups of 12 locusts were suspended on a motor-driven roundabout (25 $\mathrm{cm}$ radius) in an enclosed perspex container (volume 48.61 ) equipped with a gas flow control unit. Carbon dioxide was removed from ingoing medicinal air by $\mathrm{NaOH}$ pellets; the metabolic production of $\mathrm{CO}$, was measured continuously by chemically trapping using a titrimetric method according to RöMER et al. (1971, 1972). The amount of $\mathrm{CO}_{2}$ collected was corrected for the gas flow rate and the volume of the flight box. Resting insects suspended in the enclosed flight box served as controls.

As the total carbon dioxide produced during flight is derived from both lipid and carbohydrate oxidation, lipid oxidation was measured separately after pulselabelling of the haemolymph diglycerides with [1. ${ }^{i+}$ C]-oleic acid as described previously (VAN DER Horst et al., 1978a). Production of ${ }^{1+} \mathrm{CO}_{2}$ was registered every $5 \mathrm{~min}$ of flight or rest by taking a duplicate sample $(0.25 \mathrm{ml})$ from the titration vessel containing monoethanolamine as the trapping solution. Radioactivity was assayed in the counting medium according to JEFFAY and ALVAREZ (1961) with a Packard Model 2420 liquid scintillation spectrometer. Values were corrected for the gas flow rate, the volume of the flight box and the decrease in trapping solution during experimental time.

\section{Haemolymph analyses}

Haemolymph samples were taken with a Hamilton microsyringe from a punction in the ventral membrane between head and thorax.

Total lipids were quantified by the modified vanillin method described by Holwerda et al. (1977). For determination of diglyceride specific radioactivity. total lipids were extracted with excess chloroform. methanol, separated into lipid classes by TLC on silica gel $G$ and diglycerides eluted and quantified according to VAN DER HORST et al. (1978a). Diglyceride radioactivity was measured in Emulsifier Scintillator special MI-96 (Packard).

Total carbohydrate content was determined by a modified anthrone method (HOLWERDA et al., 1977).

Analysis of free amino acids was performed after mixing pooled haemolymph samples of 10 locusts with an equal volume of ice-cold $10^{\circ}(\mathrm{w} / \mathrm{v})$ trichloroacetic acid. The precipitate obtained by centrifugation at $12,000 \mathrm{~g}$ for $2 \mathrm{~min}$ was washed twice with $5_{\%}^{\circ}(\mathrm{w} / \mathrm{v})$ trichloroacetic acid. The combined supernatants were lyophilized and taken up into $0.5 \mathrm{ml}$ of the appropriate chromatographic buffer. Analysis was performed with a Biocal analyzer (LKB) using chromax-11 resins with lithium citrate buffers according to BENSON et al. (1967). Since addition of a reference mixture of amino acids to a haemolymph sample yielded recoveries between $96-103 \%$, the extraction procedure was considered to be adequate.

Haemolymph osmolarity was determined with a Fiske QFTM330 osmometer.

\section{RESULTS}

Flight-induced changes in haemolymph substrate concentrations

The concentrations of total carbohydrate $(27.4 \pm 6.7 \mathrm{mg} / \mathrm{ml}, n=233)$ and total lipid $(9.9 \pm 3.3$ $\mathrm{mg} / \mathrm{ml}, n=380$ ) in the haemolymph of locusts appeared to be subject to a large range in individual variations. Therefore, the effect of flight (a) (see Materials and Methods) on the concentration of these substrates was determined by comparing the changes in the mean values per group of locusts due to flight or rest.

Except after $5 \mathrm{~min}$ of flight, in all groups analyzed the changes in carbohydrate concentration are significantly correlated with the initial values, as illustrated by the correlation diagram for the $30 \mathrm{~min}$ fight period (Fig. 1): the higher the initial value. the greater is the change in carbohydrate concentration during a given period of flight. As, however, upon extrapolation the regression lines do not cross the graph's origin, a direct comparison of the changes measured during the various flight periods in different groups of locusts is not possible. Theretore, flightinduced changes in haemolymph carbohydrate

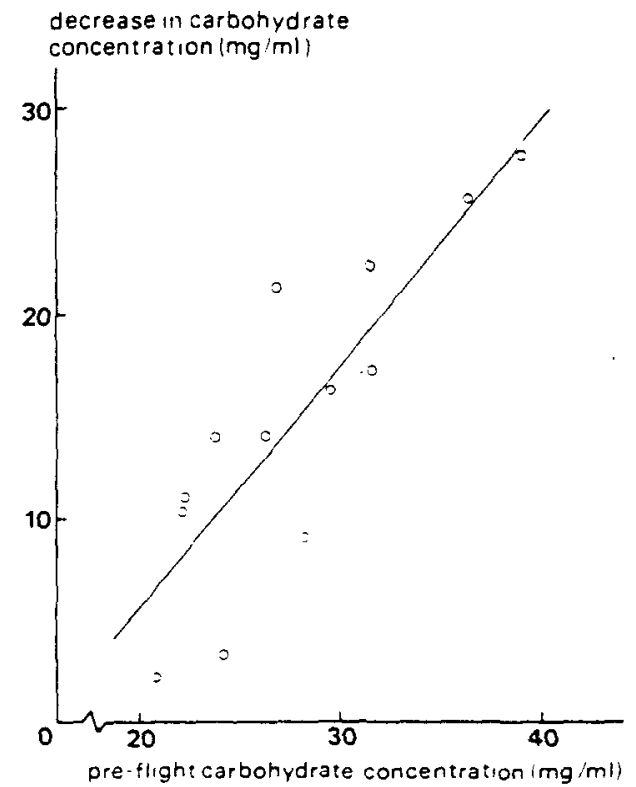

Fig. 1. Correlation $(P<0.01)$ between the decrease in haemolymph carbohydrate concentration after $30 \mathrm{~min}$ of flight and the preflight carbohydrate concentration. Cuefficient of correlation $=0.84$. 


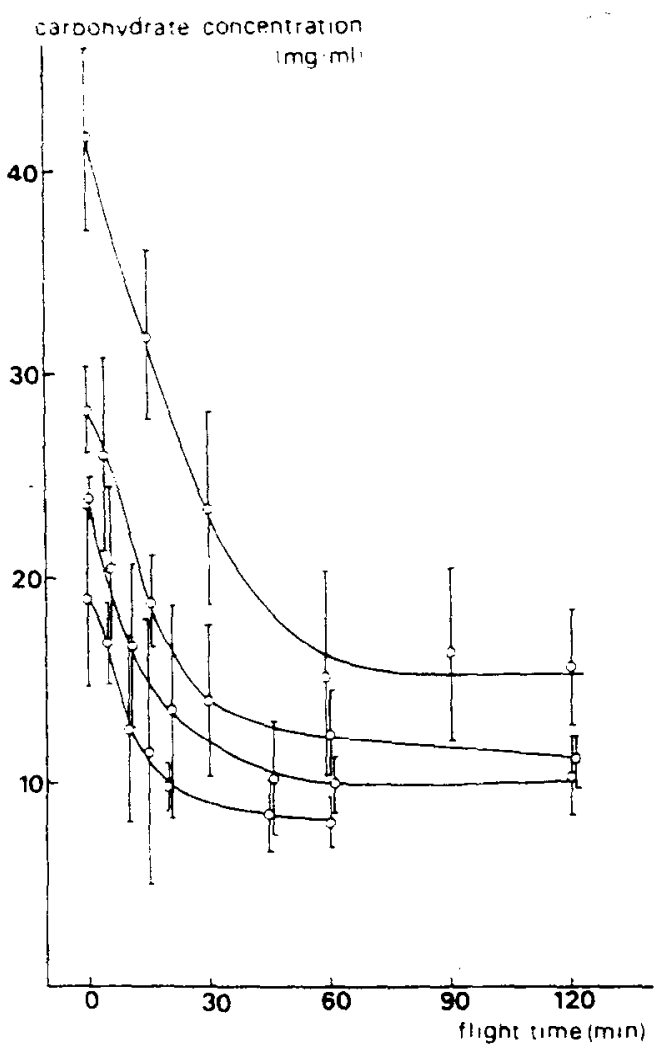

Fig. 2. Changes in the haemolymph carbohydrate concentration during flight in four groups of locusts with significantly $(P<0.01)$ different pre-flight values. Each point represents the mean \pm S.D. of three determinations.

concentration were determined by taking haemolymph samples repeatedly during flight from locusts assigned in four groups with significantly different preflight carbohydrate levels. The time course of the mean carbohydrate concentrations is shown in Fig. 2. The highest rate of decrease occurs during the first $30 \mathrm{~min}$ of llight, whereas a minimum carbohydrate concentration is reached about $60 \mathrm{~min}$ after the onset of flight. When flying activity is continued, the low level is maintained (Fig. 2). In resting locusts a small but transitory change in the concentration of haemolymph carbohydrate is observed, probably due to haemolymph sampling.

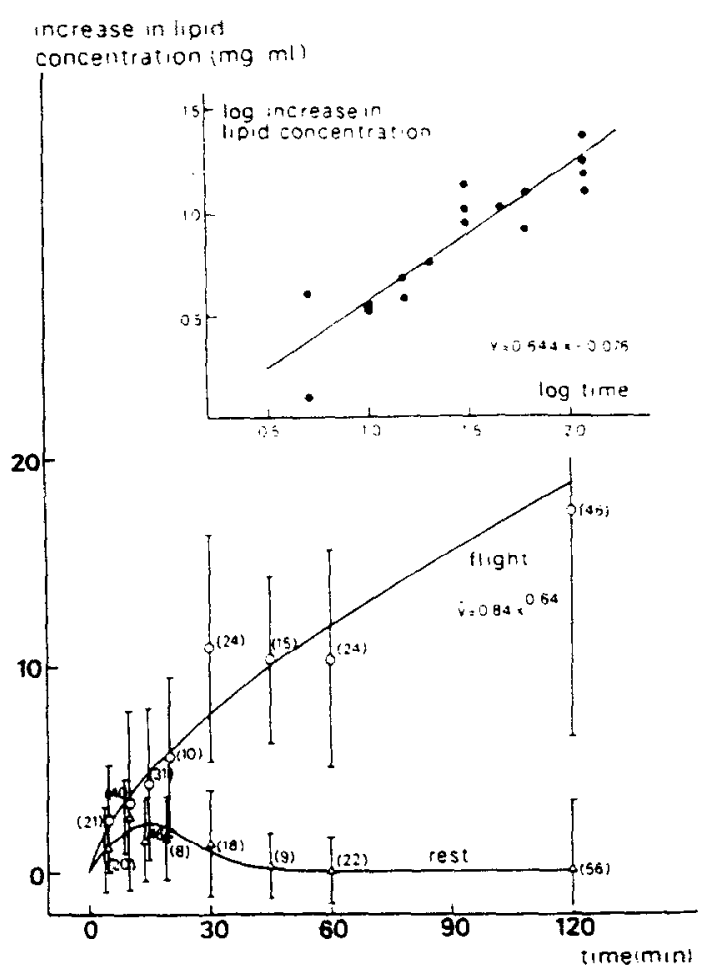

Fig. 3. Changes in the haemolymph lipid concentration of locusts during flight and at rest. Means \pm S.D. are shown. Figures in parentheses represent the number of observations. Increases in blood lipid concentrations are significantly different $(P<0.05)$ from $15 \mathrm{~min}$ on. For the double logarithmic plotting (insert), coefficient of correlation $=0.93$.

Changes in lipid concentration during flight appear to be independent of the initial values. Therefore, the absolute changes in haemolymph lipid concentration are plotted against time (Fig. 3). During flight the concentration of lipids increases, the time course of this increase is approximated by plotting the logarithm of the mean increase per group against the logarithm of time. In this double logarithmic plotting the data fit with the regression line corresponding to the equation: $\log \hat{y}=\log 0.84+0.64 \log x$, in which $\hat{y}$ is the absolute increase in $\mathrm{mg} / \mathrm{ml}$ and $x$ is the time in $\mathrm{min}$, or by transformation: $\dot{y}=0.84 x^{0.64}$. Resting locusts do also show small changes in lipid concentration (Fig. 3); in

Table 1. Changes in the concentration of some free amino acids in the haemolymph of Locusta migratoria during flight

\begin{tabular}{|c|c|c|c|c|c|c|}
\hline \multirow[b]{2}{*}{ Amino acid } & & \multirow{2}{*}{$\begin{array}{c}\text { Concentration } \\
\text { at rest } \\
(\mu \text { mole } / \mathrm{ml})\end{array}$} & \multicolumn{4}{|c|}{$\begin{array}{c}\text { Changes in concentration } \\
\text { during flight (min) }\end{array}$} \\
\hline & & & 15 & 30 & 60 & 120 \\
\hline \multirow[t]{2}{*}{ Taurine } & I & $0.16 \pm 0.02$ & +0.17 & +0.53 & +1.41 & +2.16 \\
\hline & II & $0.53 \pm 0.30$ & +0.38 & +0.89 & +2.08 & +2.25 \\
\hline \multirow{2}{*}{\multicolumn{2}{|c|}{ Glutamine }} & $4.53=0.97$ & +1.78 & +1.45 & +3.55 & +6.29 \\
\hline & & $4.25 \pm 0.63$ & +1.14 & +1.71 & +5.72 & +5.05 \\
\hline \multirow{2}{*}{\multicolumn{2}{|c|}{ Glycine }} & $4.86 \pm 0.99$ & +1.13 & +0.88 & +1.24 & +3.10 \\
\hline & & $5.97 \pm 0.69$ & +0.05 & +1.04 & +2.62 & +5.20 \\
\hline \multirow{2}{*}{\multicolumn{2}{|c|}{ Arginine }} & $0.81 \pm 0.31$ & +0.56 & +0.52 & +0.19 & +0.52 \\
\hline & & $0.62 \pm 0.10$ & +0.66 & +0.63 & +0.23 & +0.27 \\
\hline
\end{tabular}

Concentrations of free amino acids were determined in two independent analyses $(I+I 1)$. Each value is the mean \pm S.D. of four determinations on pooled haemolymph samples of ten locusts. 
Table 2. Haemolymph osmolarity and the concentration of carbohydrates and free amino acids

\begin{tabular}{lccc}
\hline & $\begin{array}{c}\text { Carbohydrates } \\
(\mathrm{mg} / \mathrm{ml})\end{array}$ & $\begin{array}{c}\text { Free amino acids } \\
(\mu \text { mole } / \mathrm{ml})\end{array}$ & $\begin{array}{c}\text { Osmolarity } \\
(\text { mosmole } \mathrm{kg})\end{array}$ \\
\hline At rest & 31.6 & 28.0 & 395 \\
After 120 min of flight & 12.7 & 39.4 & 355 \\
Change (mosmole $\mathrm{kg})$ & $-55.3^{*}$ & +11.4 & -40 \\
\hline
\end{tabular}

* Calculated on basis of trehalose. Each figure represents the value measured in pooled haemolymph samples of 25 locusts.

common with the changes in carbohydrate at rest these processes are transitory and most likely due to the stress-inducing effects of haemolymph sampling.

The concentration of single free amino acids in the haemolymph appears to be highly variable in the various groups of resting locusts measured. For the majority of the amino acids the small changes in concentration which are observed during flight are therefore not significantly different from the pre-flight levels. Significant changes in concentration occur in only the few components which are shown in Table 1: the concentrations of glutamine, glycine, arginine and particularly taurine are increasing. The changes in the total free amino acid concentration are related with haemolymph osmolarity (Table 2 ). The difference in haemolymph osmotic pressure at rest and after a 120 min flight is in fair agreement with the decrease due to the fall in carbohydrate concentration and the partial compensation caused by the rise in haemolymph free amino acids.

The effect of flight intensity on the concentration of haemolymph carbohydrate and lipid was measured in singly flown locusts (b) (see Materials and Methods) during flights of 15 and $30 \mathrm{~min}$. It was noticed again that the fall in haemolymph carbohydrate depends to some degree on the pre-flight level, whereas the change in the lipid concentration is virtually independent of the concentration before the onset of flight. In both flight periods a statistically significant correlation was established between flight speed and the changes in the carbohydrate and lipid concentrations of the haemolymph. During a certain flight period, locusts flying at higher speed show a larger decrease in haemolymph carbohydrate (Fig. 4). However, the flight-induced rise in the lipid concentration is smaller at higher flight speed (Fig. 5). During the first 15 min a relatively high flight speed even resulted in a temporary decrease in lipid concentration (Fig. 5).

\section{Substrate utilization during flight}

Total carbon dioxide production of groups of twelve locusts during flight or rest is plotted against time in Fig. 6. Resting locusts show a steady $\mathrm{CO}_{2}$ production of approximately $1.2 \mathrm{ml} \mathrm{CO}_{2} / 12$ locusts $/ 5$ min. On the commencement of flight, however, there is an exponential increase in $\mathrm{CO}_{2}$ production which results in a rather constant value of $10.2 \mathrm{ml} \mathrm{CO} / 12$ locusts $/ 5 \mathrm{~min}$ in the period of $45-60 \mathrm{~min}$ of flight; the increase in this period of flight is 8.5 times the resting value.

Carbon dioxide originating from lipid oxidation during flight was followed in locusts of which the haemolymph diglyceride pool was labelled with $[1-1+C]$-oleic acid. ${ }^{1+} \mathrm{CO}_{2}$ production of groups of twelve locusts is shown in Fig. 7. The amount of ${ }^{14} \mathrm{CO}_{2}$ produced is dependent on the rate of diglyceride oxidation in the flight muscles and on the concentration of radiolabelled haemolymph diglycerides. Latter concentration is the resultant from a decrease of the initial radioactivity by mobilization of unlabelled diglycerides from lipid stores on the one hand and utilization of labelled substrate on the other.

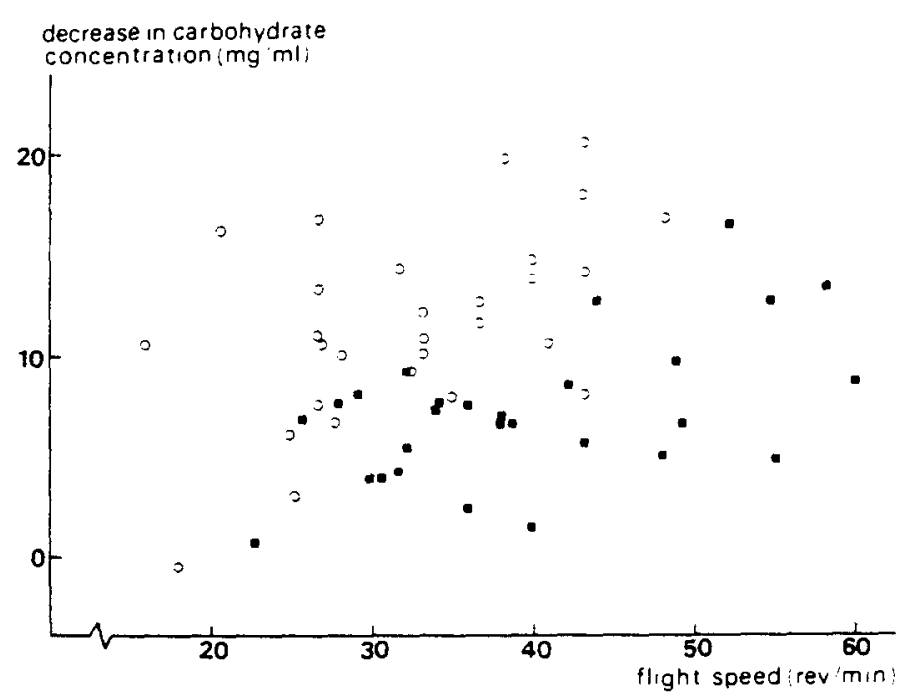

Fig. 4. Scatter diagram showing the correlation between the decrease in the haemolymph carbohydrate concentration and the flight speed during flights of $15 \min (\mathbf{E} . P=0.01)$ and $30 \mathrm{~min}(00, P<0.025)$. 


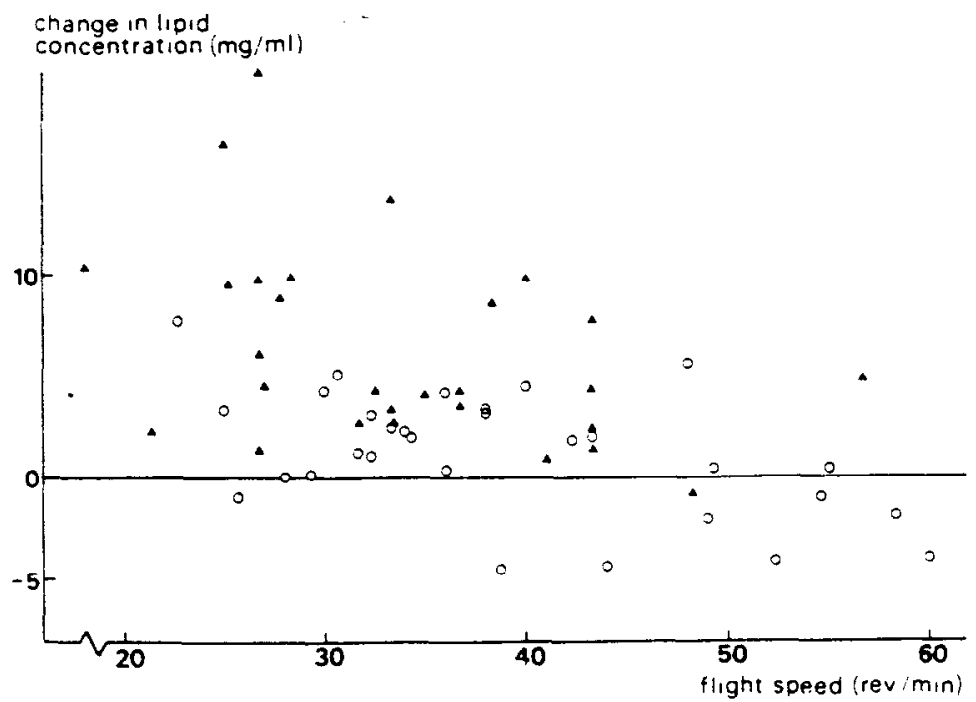

Fig. 5. Scatter diagram showing the correlation between the changes in the haemolymph lipid concentration and the flight speed during flights of $15 \min (0 O, P<0.025)$ and $30 \min (\Delta \Delta . P=0.025)$.

These changes in specific radioactivity of the haemolymph diglycerides are plotted against time in Fig. 8. Presuming the principal diglycerides to contain two $C_{18}$ fatty acids (BEENAKKERS, 1973), oxidation of $1 \mathrm{mg} \dot{\mathrm{C}}_{36}$-diglyceride will result in the production of $1.29 \mathrm{ml} \mathrm{CO}$. Using this value in the correlation between ${ }^{1+} \mathrm{CO}$, recovered (Fig. 7) and specific radioactivity (Fig. 8), $\mathrm{CO}_{2}$ production from diglyceride fatty acid oxidation can be calculated and is shown for locusts during flight in Fig. 9. It is apparent that lipid oxidation in the flight muscles due to flying activity is changing with time: the slope of the curve is increasing until after approximately $45 \mathrm{~min}$ of flight, maximum diglyceride oxidation is obtained. Total diglyceride utilization during the $1 \mathrm{hr}$ flight period is about $2.1 \mathrm{mg} /$ locust.

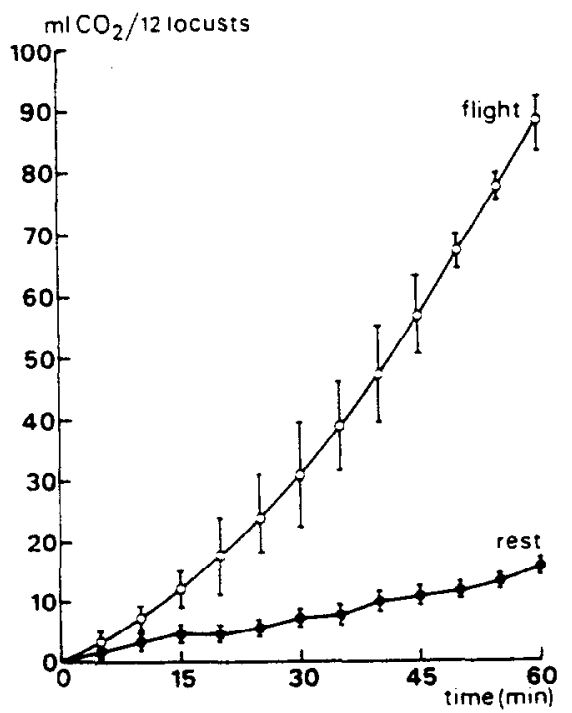

Fig. 6. Total carbon dioxide production from groups of twelve locusts during flight or rest. Means \pm S.D. are given $(0-15 \min : n=10 ; 20-30 \min : n=7: 35-60 \mathrm{~min}: n=4)$

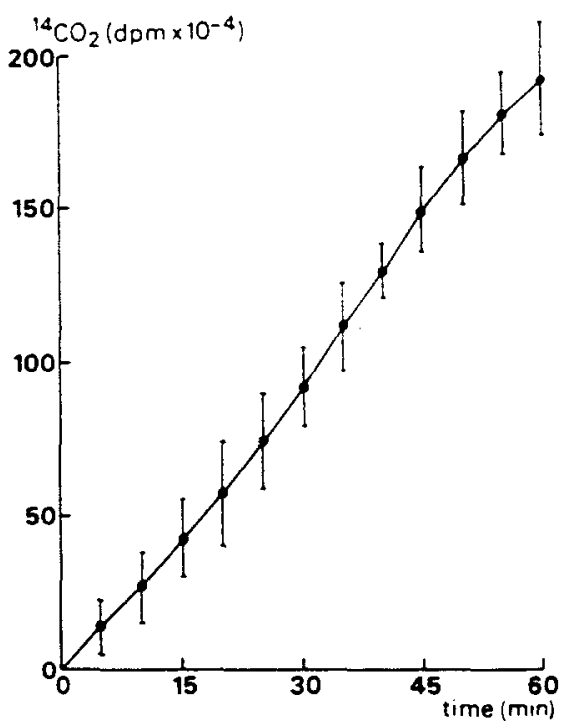

Fig. 7. Total radioactivity of respired ${ }^{14} \mathrm{CO}_{2}$ in groups of twelve locusts during flight after pulse-labelling of the haemolymph diglycerides with $[1-1+\mathrm{C}]$-oleic acid. Means \pm S.D. are shown $(0-15 \mathrm{~min}: n=7 ; 20-30 \mathrm{~min}: n=5 ; 3 j-60 \mathrm{~min}$ : $n=3)$.

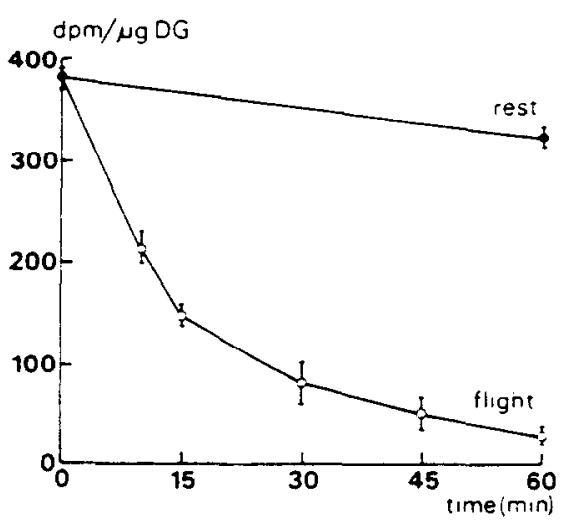

Fig. 8. Decrease in specific activity of the haemolymph diglycerides labelled with $[1-1+C]$-oieic acid during flight or rest. Each point represents the mean $\pm S . D$. of three groups of twelve locusts. 


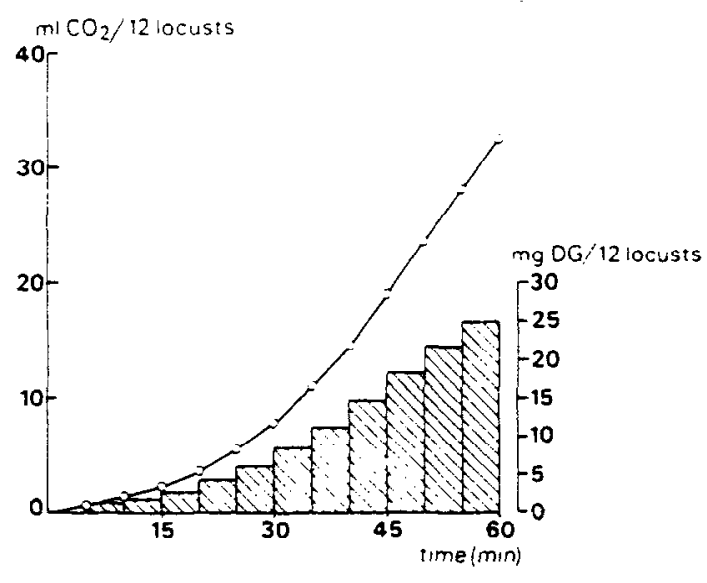

Fig. 9. Carbon dioxide production from a group of twelve locusts due to diglyceride fatty acid oxidation during flight. Calculations are based on ${ }^{14} \mathrm{CO}_{2}$ production during flight (Fig. 7) and the change in specific radioactivity of the haemolymph diglycerides (Fig. 8). Total amounts of diglycerides oxidized during flight are shown as well.

\section{DISCUSSION}

In order to meet the high metabolic demands in flight, the flight muscles of the locust must be supplied continuously with ample substrate. Therefore, the apparent metabolic strategy of the two-fuel system may be an efficient adaptation, since initially the muscle cells utilize the directly available high amount of trehalose in the nearby haemolymph, whereas the more time-consuming processes of lipid mobilization from stores in other parts of the body and transport to the muscles come into prominence as flight is continued. The high concentrations of these flight fuels in the haemolymph may be necessary to provide a constant supply of metabolites to the muscles.(WEIsFogh, 1964; Crabtree and Newsholme, 1975), the relatively inefficient circulation compared to the capillary system of vertebrates taken into account. As flight does not result in a change in haemolymph volume (BEENAKKERS, 1973; JUTSUM and GOLDSWORTHY, 1976) the shatp decrease in carbohydrate concentration on the commencement of flying activity reflects an actual reduction of the haemolymph stores. Since mobilization of trehalose from other body carbohydrate reserves is hardly occurring during the first half hour of flight (VAN DER HoRsr et al., 1978b) carbohydrate concentration can be expected to decrease in proportion to the metabolic rate in the flight muscles. Indeed it is found that the carbohydrate concentration decreases more rapidly if flight speed is higher (Fig. 4). Furthermore, the fall in carbohydrate concentration appears to depend also on the pre-flight level. Utilization is more pronounced in locusts with a high pre-flight level compared to locusts with a lower initial concentration. However, a definite correlation between initial carbohydrate concentration and flight speed could not be demonstrated. In spite of the observed positive correlation between the decrease in carbohydrate concentration and the pre-flight level, post-flight levels are higher as initial levels are higher (Fig. 2). The persistent low carbohydrate concentration during sustained flight has been shown to be a steady state. in which the rate of mobilization of trehalose from body carbohydrate stores is matched by the rate of utilization in the flight muscles (VAx DER Horst et al., 1978b). Whether or not hormonal factors are involved in the regulation of this steady state flight level is not clear; although hyperglycaemic faciors are present in the locust corpus cardiacum, injection of corpus cardiacum extracts in fully developed locusts does not evoke a hyperglycaemic response (GOLDSWORTHY. 1969; BEENAKKERS et al., 1978).

The rise in haemolymph lipid concentration during flight is in accordance with earlier observations on flight-induced mobilization of diglycerides from fat body triglyceride stores (TIETZ, 1967; BEENAKKERS. 1973, JUTSUM and GOLDSWORTHY, 1976; VAN DER HORST et al., 1978a). In this process an adipokinetic hormone is involved, which is syuthesized in the glandular lobe of the corpus cardiacum (GOLDSWORTHY et al, 1972) and released at an increased rate during flight (CHEESEMAN and Goldsworthy, 1976; Houben and BeENakKers. 1976; RADEMAKERS and BEENAKKFRS, 1977). In contrast to the changes in carbohydrate level. the increase in haemolymph lipid concentration during flight on motor-driven roundabours appears to be independent of the initial value, indicating immediate mobilization of lipids at the onset of flight. In view of the two-fuel system of Locusta it would be conceivable to suppose a relationship between the initial value of haemolymph carbohydrate and the increase in lipid concentration during flight, as experimentally produced high concentrations of disaccharides (trehalose, sucrose) in the haemolymph of flying locusts prevent the release of the adipokinetic hormone (CHEESEMAN et al., 1976; Vax DER HORST et al., 1979), which is reflected in the absence of an elevation of the haemolymph lipid level. However, in spite of the significantly different pre-flight carbohydrate levels in the various groups of locusts used, no delay in lipid mobilization was established, suggesting the apparent absence of a mechanism for simultaneous control of the two parallel processes, viz. carbohydrate oxidation and lipid release. Since the changes in the haemolymph lipid concentration during flight can be regarded as the net result of the rates of mobilization and utilization it is of interest that in locusts flying very fast on the roundabout without mechanical propulsion, lipid concentration decreased during the first $15 \mathrm{~min}$ (Fig. 5). From this effect it is already apparent that lipid oxidation occurs even during the early stages of night, which is in agreement with previous estimations of lipid utilization (JUTSUM and GOLDSWORTHY, 1976: VAN DER HORST ef al, 1978a, b). The respiration experiments reported here substantiate these observations, as carbon dioxide production from labelled haemolymph diglycerides immediately increases on the initiation of flight (Fig. 8). Lipid oxidation reaches a plateau value after about $45 \mathrm{~min}$ of flight, though haemolymph lipid levei continues to rise (Fig. 3) until, after some 2 hr of flight, a steady state level is attained (VAN DER HORST et al., 1978a). The oxidation rate of approximately $10 \mathrm{mg}$ diglycerides 12 locusts in the period of $45-60 \mathrm{~min}$ of flight (Fig. 8) is in 
close agreement with the data obtained from haemolymph diglyceride turnover rates in locusts during longer $(2-6 \mathrm{br})$ flights, $v i z, 10.2 \mathrm{mg}$ diglycerides 12 locusts $15 \mathrm{~min}$ (VAN DER HORST $e t \mathrm{al}$., 1978a). It should be noted that in all experiments tethered flight conditions were used; in migratory flight figures may be significantly higher. From the simultaneous increase in flight muscle lipid oxidation. and haemolymph lipid concentration in the desert locust Schistocerca gregaria, MAYER and CANDY (1969a) suggested the rate of lipid oxidation to be partly controlled by the concentration of diglycerides in the haemolymph. This may be true for Locusta as well.

Some free amino acids appear to accumulate in the haemolymph of insects during flight, but with the exception of proline (KIRSTEN et al.. 1963: BLRSELL, 1967: CrabtreE and Newsholme. 1970: De Kort et al. 1973: HANSFORD and JOHNSON. 1975) no evidence for a direct use of free amino acids as energy substrates for flight has been reported so far. However, the observed increase in glutamate can possibly be viewed in the light of a flight-induced elevation of transamination processes as recent experimental evidence suggests that on the initiation of flight. part of the tricarboxylate cycle intermediates in the flight muscle mitochondria of the locust may be supplied by glutamate, which would thus act as a "sparker" (WORM and BCENAKKERS. 1979). The arginine concentration could be raised as the result of hydrolysis of argininephosphate, a phosphagene of insect flight muscles (GILMOUR, 1965). Regarding a possible role of taurine, the amino acid the most markedly increased in haemolymph concentration during flight, several suggestions generally have been made, varying from a function as neurotransmitter (KACZMAREK and DAvison, 1971) to a role as an osmoregulator (WIGGLESWORTH, 1949). Flight activity of Locusta results in a decrease of haemolymph osmolarity due to the decrease in carbohydrate concentration. The concomicant flight-induced stimulation of lipid release will not affect osmolarity as haemolymph lipids are transported through lipoproteins. As shown in Table 2. the increase of total concentration of haemolymph free amino acids will only partially counterbalance the fall in haemolymph osmolarity: after a $2 \mathrm{hr}$ flight compensation by free amino acids is only some 20 per cent.

Acknowledgement-The help of Mr. A. H. KLEINE in the performance of the respiration experiments is gratefully acknowledged.

\section{REFERENCES}

BeEvakkers A. M. TH. (1969a) Carbohydrate and fat as a fuel for insect flight. A comparative study. J. Insect Phisiol. 15, 353-361

BeENiKKERS A. M. TH. (1969b) The influence of corpus allatum and corpus cardiacum on lipid metabolism in Locusia migratoria. Gen. comp. Endocr. 13, 12.

BEEX+KKERS A. M. TH. (1973) The infuence of light on lipid metabolism in Locusta migratoria. Insect Biochem. 3, 30 :-308.

BeENikkers A. M. Th., VAN Der Horst D. J. and VAN MARREWUJ W. J. A. (1978) Regulation of release and metabolic function of the adipokinetic hormone in insects. In Comparative Endocrinology (Ed by GaILLaRD P. I and BOER H. H.). pp. H5-418. Elsevier. Amsterdam.

BeNSON J. Y., Gordon . II. J. and Pattersox J. A. (1967) Accelerated chromatographic analysis of amino acids in physiological tluids containing glutamine and asparagine. Anal. Biochem. 18, 228-240.

BCRSELL E. (1967) The conversion of glutamate to alanine in the tsetse tly (Glossina morsians). Comp. Biochem. Phyiol. 23, 825-829.

CANDy D. J. (1970) Metabolic studies on locust tighr muscies using a new perfusion technique. $J$. Insect Ph:siol. 16. 531-543.

ChfFefiay P and Goldsuorthy G. J. (1976) Studies on the dynamics of the release of locust adipokinetic hormone. Gen. Comp. Endocr. 29, 292.

Cheesemav P. Jutsiu A R and Golosworthy G J (1976) Quantitative studies on the release of locust adipokinetic hormone. Phisiol. Ent 1. 115-121.

CRABTREF B. and NeWSHOL ME E. A (1970) The activities of proline dehydrogenase. glutamate dehydrogenase. aspartate-oxoglutarate aminotransterase and alanineoxoglutarate aminotransferase in some insect flight muscles. Biochem. J. 117, 1019-1021

Crabtree B. and Newsholme E. A. (1975) Comparative aspects of fuel utilization and metabolism by muscle In

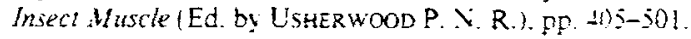
Academic Press. London.

DE KORT C. A. D. BARTFINK A. K. M and SCHLlRuans R. R. (1973) The significance of L-proline for exidative metabolism in the flight muscles of the Colorado beetle, Leptinorarsa decemlineara. Invect Biodiem. 3, 11-1:

GiLmolir D. (1965) The . Hetabolism of Insects. Oliver \& Boyd, Edinburgh.

GoLDSWORTHY G.J. (1969) Hyperglycaemic factorifom the corpus cardiacum of Loctista migratoria. J. Insect Physiol. $15,2131-21+0$.

Goldsworthy G. J.. MordLe W.. and Gittkeich J. (1972) Studies on insect adipokinetir hormones. Ge? comp. Endocr. 18, $545-551$.

HA.VSFORO R. G. and Jorssox R. N. (1975) The nature and control of the tricarboxylate cycle in beetle flight muscle. Biochem. J. 148, 389-401.

Holwerda D. A., Van Dooris J. and Beesiakkers A. M. Th. (1977) Characterization of the adipokinetic and hyperglycaemic substances from the locust corpus cardiacum. Insect Biochem. 7, 151-157.

HolbeN N. M. D. and Beesakkers A. M. Th. (1976) Demonstration of adipokinetic activity in haemolymph from flown locusts. Gen. comp. Endocr, 29, 291-292

JEFFAY H. and ALVAREZ J. (1961) Liquid scintillation counting of carbon-14. Use of ethanolamine-thylene glycol monomethyl ether-toluene. Anal. Chem. 33. 612.

JLTSLM A. R. and GOLDSwORTHY G. J. (1976) Fuels for flight in Locusta. J. Insect Phisiol. 22, 243-249.

Kaczmarek L. $K$. and Davison $A .>119^{-1}$ The phusiolovical role of taurine. Biochem $f .123$, t.P

Kirstex E.. Kirstex R. and ARese P. (1963) Das Verhalten von freien Aminosïuren. energiereichen PhosphorsäureVerbindungen und einigen Glykolyse- und Tricarbonsäurecyclus-Substraten in Muskeln von Locusta migratoria bei der Arbeit. Biochem. Z. 337, 16:-178.

MAYER R. J. and CANDY D. J. 1967) Changes in haemolymph lipoproteins during losust thight. Nature. Lond. 215.987.

MAYER R. J. and CANOY D. J. (1969a) Changes in energy reserves during flight of the desert locust. Schistocerca gregaria. Comp. Biochem. Physiol. 31, $\div 09-418$.

MaYer R. J, and CANDY D. J. (1969b) Conticl of haemolymph lipid concentration during locust ilght: an adipokinetic hormone from the corpora cardiaca. J. Insed Phisiol. 15, 611-620.

MWAigi R. W. and Goldsworthy G. J. (1977) Digiveride- 
transporting lipoproteins in Locusta. J. comp. Physiol. 114, 177-190.

PeLed Y. and TIETZ A. (1975) Isolation and properties of a lipoprotein from the haemolymph of the locust, Locusta migratoria. Insect Biochem. 5.61-72.

Rademakers L. H. P. M. and BeENikkers A. M. TH. (1977) Changes in the secretory activity of the glandular lobe of the corpus cardiacum of Locusta migratoria induced by flight. Cell Tiss. Res. 180, 155-171.

Römer F. G.. VaN Osch G. W. S. and Griepink B. (1971) Über die Automatisierung der Kohlenstoff- und Wasserstoffbestimmung in $\mu \mathrm{g}$-Mengen organischer Substanz. 1. Mikrochim, Acta (Wien) 1971:5, 772-777. RÖMER F. G.. VAN OSCH G. W. S.. Buis W. J. and GRIEPINK B. (1972) Uber die Automatisierung der Kohlenstofbestimmung. II. Mikrochim. Acta (Wien) 1972 5, 674-679.

TIETZ A. (1967) Fat transport in the locust: the role of diglycerides. Eur. J. Biochem. 2, 236-242.

Vaiider Horst D. J.. Baljet A. M.C.. Beenakkers A. M. Th. and VAN HaNDEL E. (1978a) Turnover of locust haemolymph diglycerides during flight and rest. Insect Biochem. 8, 369-373.

VaN Der Horst D. J., VA.N DoorN J. M., and Beenakkers
A. M. TH. (1978b) Dynamics in the hacmolymph trehalose pool during flight of the locust. Locusta migratoria. Insect Biochem. 8, $413-416$.

Vai Der Horst D. J., VaN Door:y J. M. and BeENakKers A. M. TH. (1979) Effects of the adipokinetic hormone on the release and turnover of haemolymph diglycerides and on the formation of the diglyceride-transporting lipoprotein system during locust flight. Insect Biochem. 9 , 627-635.

WEIS-FOGH T. (1952) Fat combustion and metabolic rate of flying locusts (Schistocerca gregaria Forskảl). Phil. Trans. R. Soc. B. $237,1-36$.

WEIS-FOGH T. (1964) Functional design of the tracheal system of flying insects as compared with the avian lung. J. exp. Biol. 41, 207-227.

WigGleswORTH V. B. (1949) The utilization of reserve substances in Drosophila during flight. J. exp. Biol. 26. 150-163.

Worm R. A. A. and BeEnakkers A. M. TH. (1979) Regulation of substrate utilization in the flight muscle of the locust, Locusta migratoria. during flight. Insect Biochem. 10, 53-59. 